\title{
Clause by clause: the reasoning in the Stormont House Agreement 'Model Bill' on dealing with the past in Northern Ireland
}

\author{
Kieran McEvoy, Anna Bryson, Brian Gormally, Daniel Greenberg, Jeremy Hill, \\ Daniel Holder, Louise Mallinder and Gemma McKeown*
}

\section{Introduction}

1. These explanatory notes relate to the Model Implementation Bill for the Stormont House Agreement prepared by a drafting committee led by Professor Kieran McEvoy comprised of representatives from Queen's University Belfast, Ulster University and the Committee on the Administration of Justice. These notes have been prepared in order to assist the reader of the Model Bill and to help inform debate on it (referred to as 'the Act' in the text of the Model Bill).

\section{Summary and background}

2. The Model Bill would, if enacted, give legislative effect to particular elements of the Stormont House Agreement (SHA), which was published on 23 December 2014 following negotiations between the British and Irish governments and the political parties in the Northern Ireland Executive. In addition to the provisions relating to 'The Past', the Stormont House Agreement contains provisions on: finance and welfare; flags, identity, culture and tradition; parades; institutional reform; outstanding commitments; and review and monitoring. These provisions are not contained in this Model Bill and will not, as we understand it, be included in the UK government's planned legislation which will focus exclusively on the past-related elements of the Agreement.

3. The drafting committee was keen that the government's draft Bill should not be the only starting point for public debate. We wished to ensure that civil society in Northern Ireland had a full opportunity to contribute to the legislative process; to ensure full compliance with the UK's international obligations, particularly Article 2 of the European Convention on Human Rights (ECHR); and to follow closely the principles in paragraph 21 of the SHA:

... an approach to dealing with the past . . . which respects the following principles: promoting reconciliation; upholding the rule of law; acknowledging and addressing the suffering of victims and survivors; facilitating the pursuit of justice and information recovery; is human rights compliant; and is balanced, proportionate, transparent, fair and reasonable.

* The authors would like to acknowledge the financial assistance of the Arts and Humanities Research Council (Grant Reference AH/J013897/1) and the Queen's University Belfast Business Alliance. The authors' affiliations are as follows: Kieran McEvoy and Anna Bryson, Queen's University Belfast; Brian Gormally, Daniel Holder and Gemma McKeown, Committee on the Administration of Justice; Daniel Greenberg, barrister specialising in legislation and the legislative process; Jeremy Hill and Louise Mallinder, Ulster University. 
We believed that drafting this Model Bill, in addition to the various other policy outputs produced by the team over the past number of years would enhance that process.

4. The SHA contains much less detail than the proposals on the past put forward by Dr Richard Haass and Professor Meghan O'Sullivan (Haass-O'Sullivan proposals) during the earlier negotiating process which ended in late 2013. There are many issues where the SHA has left the detail of implementation for later resolution. Our Model Bill, which we wish to focus more directly on Article 2 compliance and the 'paragraph 21 principles' in the SHA, proposes alternative solutions to the leaked Westminster draft Bill on some of these issues.

\section{Overview}

\section{PART 1 PRELIMINARY}

5. This Part sets out the 'founding principles' (which are to be found in paragraph 21 of the SHA) and how they are to be applied and provides definitions for some key concepts that will be used throughout the Model Bill.

\section{Part 2 Historical InVESTIGations Unit}

6. This Part deals with the establishment, functions, powers and all other aspects of the Historical Investigations Unit (HIU).

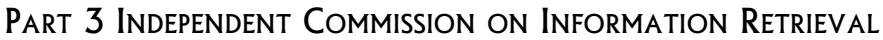

7. This Part deals with the establishment, functions and powers of the Independent Commission on Information Retrieval (ICIR) and implements the proposed text of the international Agreement between the UK and Ireland.

\section{Part 4 Implementation and Reconciliation Group}

8. This Part deals with the establishment, functions and powers of the Implementation and Reconciliation Group (IRG). It makes provision for the report on themes and determines the IRG's relations with other legacy bodies.

\section{Part 5 Oral History Archive}

9. This Part establishes the Oral History Archive (OHA) and makes provision for the collection of new oral history material and collaboration with existing oral history projects. It also makes provision for the confidentiality of contributions in certain cases.

\section{Part 6 General}

10. This Part deals with interpretation of various terms and the procedure for regulations.

\section{Schedule 1 Staff and Proceedings of the Director of the HiU}

11. This detailed schedule is not included in the Model Bill. The schedule would contain the details of information such as arrangements for staff pensions and conditions, applicability of a Code of Ethics and other matters. Section 5 makes reference to this schedule.

\section{Schedule 2 Text of the Agreement between the United Kingdom and IReland on THE ESTABLISHMENT OF THE INDEPENDENT COMMISSION ON INFORMATION RETRIEVAL}

12. This is the proposed text for an inter-state treaty between the UK and Ireland which will be necessary to establish the ICIR as an international body with jurisdiction throughout the $\mathrm{UK}$ and Ireland. 


\section{Commentary on sections}

\section{PART 1 PRELIMINARY}

\section{Section 1 Founding principles}

13. Section 1 deals with the principles which the SHA states (paragraph 21) must be respected in the approach to dealing with the past. Sub-section (1) requires that the principles be considered by public authorities exercising functions under the Act and by courts and tribunals in interpreting it.

14. Sub-section (3) codifies the principles in a form suitable for legislation. Sub-section (3)5 interprets the reference to human rights compliance in the SHA as the need to protect the rights guaranteed by the ECHR as defined by the Human Rights Act and other international standards. These latter include a range of principles and guidelines relating to investigations and justice for victims, but will also include relevant texts such as the Convention on the Elimination of Discrimination Against Women, UN Resolution 1325 on the role of women in peacebuilding and the Convention on the Rights of the Child. The stronger language in 3(5) providing that fundamental rights 'must' be protected reflects the nature of such rights as international obligations.

\section{Section 2 Definition of 'troubles-related'}

15. Section 2 seeks to define 'troubles-related' in the context of deaths and human rights breaches. troubles-related deaths is the term used in paragraph 30 of the SHA. Various bodies have adopted different start dates for the beginning of 'the Troubles'. However, the Victims and Survivors (Northern Ireland) Order 2006 (2006 No 2953) defines 'conflict related incident' as an incident appearing to the Commissioner (for Victims and Survivors) to be a violent incident occurring in or after 1966 in connection with the affairs of Northern Ireland. Sub-section (1) adopts the same start date and refers to deaths which occurred in connection with political conflict in Northern Ireland. No end date is specified in the SHA and is therefore not provided for in the Model Bill. The SHA does provide that the initial case list of the HIU will be made up of outstanding cases from the Police Service of Northern Ireland (PSNI) Historical Enquiries Team and legacy branch of the Police Ombudsman, both of which have a timeframe finishing in 1998. Whilst this will constitute the bulk of the HIU caseload, it does leave open the opportunity for families to bring new cases to the HIU, where there is new evidence, for which this cut-off date does not apply. This leaves open the possibility of the various mechanisms provided for by the SHA examining some cases that may be seen as transitional between the conflict and the contemporary justice system.

16. The founding principle of human rights compliance requires that any investigative obligation imposed by international standards, and particularly by the ECHR, be carried out by the appropriate mechanism established by this legislation. Sub-section (2) defines a 'qualifying human rights breach' as a breach of Articles 2 or 3 of the ECHR in connection with political conflict in Northern Ireland. Article 2 ECHR imposes investigative obligations on the state in the case of deaths and Article 3 imposes obligations in cases of harm occasioned through torture or inhuman or degrading treatment. The effect of this will be to bring qualifying conflict-related cases of attempted murder or serious injury relating to the Troubles within the purview of the HIU. They will be qualifying cases where they have involved a breach (i.e. a violation) of human rights by the state (such as a breach of the investigative obligation of Article 3 ECHR). The inclusion of this provision reflects the reality that there otherwise would be a group of cases that the state must investigate to meet ECHR requirements, but would 
otherwise have no competent institution to conduct such investigations. The Police Ombudsman can only investigate the actions of police officers, and the PSNI lacks the necessary independence to investigate state involvement cases. Whilst it would be open to the state to establish an entirely separate body to the HIU which mirrors its powers and independence, it would appear more practical to extend the HIU's remit to deal with such cases.

17. Sub-section (3)(a) and (b) seek to close a gap whereby the deaths of persons who died as an indirect result of a conflict-related incident, for example, after suffering a heart attack on witnessing an incident or as a result of injuries sustained in an incident, might otherwise not be included in the remit of the relevant mechanism. Sub-section (3) also intentionally does not contain a geographical limitation on where the death or qualifying human rights violation must have occurred. The intention is that such matters where related to the Northern Ireland conflict, and hence the conspiracy or other actions relating to them will have taken place within UK jurisdiction, can be investigated by the HIU. This would cover situations whereby deaths occurred in the Republic of Ireland or Great Britain but also the smaller number of cases elsewhere. The disclosure powers of the HIU will only extend to UK public authorities, and its policing powers to Northern Ireland, yet it is intended the HIU can seek the cooperation of police forces in Great Britain in the same manner as the PSNI and cooperation with authorities in other jurisdictions through existing arrangements. There is specific explicit provision for this in the SHA in relation to the Irish authorities.

\section{Section 3 Definition of 'perpetrator'}

18. Section 3 follows international standards, and in particular Article 25(3) of the Rome Statute, which established the International Criminal Court, in positing a definition of perpetrator which goes beyond the person who physically carried out the killing etc. Subsection (1)(b) and (c) include a person who ordered or knowingly facilitated an offence which resulted in a death in the definition of perpetrator. Sub-section (2)(a) provides that an offence includes an attempted offence and that facilitating an offence includes doing anything designed to encourage the commission of the offence. For the avoidance of doubt the definition of perpetrator includes 'state actors', namely those acting in some capacity on behalf of a public authority.

19. Sub-section (3) provides that, for the purposes of the HIU, an offence includes professional misconduct. This is to enable HIU to investigate cases transferred from the Office of the Police Ombudsman for Northern Ireland where the alleged behaviour of police officers may amount only to misconduct rather than criminality. In compliance with the SHA principle of fairness and equality this provision covers misconduct by any institution rather than solely the police.

\section{Section 4 Definition of 'investigating bodies'}

20. Section 4 lists the organisations covered by the term 'investigating bodies' in the Model Bill.

\section{PART 2 HISTORICAL INVESTIGATIONS UNIT}

\section{Section 5 Establishment of HIU}

21. The drafting committee understands that the official Stormont House Implementation Group has agreed that the First and Deputy First Ministers should appoint the Director of the HIU in consultation with the Department of Justice; sub-sections (2) and (3) would implement this decision. The SHA does not specify this process and alternative arrangements ensuring an independent and effective appointment could be entered into. 
Sub-section (4) seeks to ensure that the appointee has credibility with relevant stakeholders, including victims' groups, and that a public statement evidencing the qualifications of the appointee for the post is made.

22. Sub-section (5) specifies that the Director of the HIU is to be a corporation sole. This is the same status as the Police Ombudsman and Director of Public Prosecutions and means that the Director in person possesses the characteristics of a body corporate. This means that the obligations, powers and decision-making capacity of the organisation are vested in the Director as an individual rather than in a group or committee of people. The drafting committee believes that this is the legal construction most likely to facilitate the independence of the HIU.

23. Sub-section (6) places a statutory duty on the HIU Director to take reasonable steps to secure a gender balance in HIU staff and that HIU staff have the expertise and aptitude to take a gender-sensitive approach. The former provision is similar to that provided for in legislation for bodies such as the Parades and Human Rights Commissions which is aimed at securing that the composition of Commissioners bodies is reflective of community background in Northern Ireland. We have not replicated a similar provision on the basis of community background in recognition that, given the requirements of independence, many HIU staff will be persons from outside of Northern Ireland. The second provision in relation to gender expertise draws on international standards. Sub-sections (7) and (8) make provision for the Policing Board to issue a Code of Ethics setting out standards for HIU staff, including compliance with ECHR and other human rights standards. This is similar to the existing code for PSNI officers. Sub-section (8) defers the detail of this and other staffing matters to Schedule 1.

\section{Section 6 Family support staff}

24. Section 6 provides for the appointment of the HIU family support staff in accordance with paragraph 33 of the SHA. Sub-section 2 makes clear that this is a complementary role to the rights of next of kin to be involved in an investigation. This is aimed to, for example, preclude a scenario whereby access to and engagement with investigators is actually curtailed or limited on grounds of the existence of family support staff.

\section{Section 7 Independence}

25. Independence is a key element of the investigative obligation established under Article 2 (right to life) of the ECHR; sub-section (1) formulates the basic principle that there must be no connection between those investigating and those whose behaviour is being, or may be investigated, in the light of Article 2 jurisprudence. The legal meaning of 'persons' includes organisations and institutions as well as individuals.

26. Sub-section (2) clarifies that 'connection' includes past as well as present connection and also reasonably perceived or suspected as well as actual connection.

27. Sub-section (3) specifies that it is not just the investigating officers on the ground who must have no connection with those potentially being investigated, but also all those who may be engaged in the provision of research, archiving or other support functions.

28. Sub-section (4) specifies that persons that have been members of organisations which were engaged in the conflict, lawfully or not, and which therefore might come under investigation, would be debarred from employment by the HIU. The debarring of members and ex-members of the Royal Ulster Constabulary and the British Army is similar to the position adopted by the Police Ombudsman in its legacy cases. It also precludes persons who have paramilitary convictions. The purpose of this provision is to avoid doubt 
and legal challenge to decisions made under sub-section (1). Sub-section (5) notes that subsection (4) does not affect the generality of sub-section (1).

29. Sub-section (6) explicitly links the founding principle of human rights compliance to the HIU and provides that it must have regard to the broad range of human rights instruments (both 'hard' and 'soft' law) which relate to the independence and other desirable characteristics of investigative mechanisms.

\section{Section 8 Finance}

30. Section 8 seeks to ensure that the independence of the HIU is not compromised by the manipulation, deliberate or due to general austerity, of the budget by a sponsoring department. The specifications that the UK Treasury must determine the HIU's budget and that it must be paid out of the Consolidated Fund mean that Parliament would decide the figures and they could only be changed by a relevant vote in Parliament.

\section{Section 9 Five-year target}

31. Section 9 provides for a five-year target for the HIU to complete its work as referenced in the SHA, though beginning when the legislation comes into force rather than at the date of the Agreement. If that timeframe does not prove viable, sub-section (2) gives a power to the Secretary of State to amend the completion date by regulation.

32. Sub-section (3) states that the Secretary of State must make provision for such an increase if one of two conditions is satisfied. Sub-section (3)(a) states as the first condition that the Secretary of State is satisfied that international human rights obligations demand a continuation of the work of the HIU. This circumstance is most likely to arise if there are outstanding cases to which the Article 2 investigative obligation applies and there is no suitable alternative mechanism available to carry out the investigations. Sub-section (3)(b) states as the second, alternative condition, that the First and Deputy First Ministers believe there is uncompleted work which the HIU should be allowed to finish.

\section{Section 10 Duty to carry out investigations}

33. This section sets out the basic investigative duty of the HIU. Sub-section (1)(a) specifies the duty to investigate troubles-related deaths. Sub-section (1)(b) specifies the duty to investigate alleged or suspected troubles-related human rights breaches (limited by section 2(2) to breaches of Article 2 or 3 ECHR). As noted in paragraph 16 of these explanatory notes, Article 3 ECHR (freedom from torture and inhuman and degrading treatment), as well as Article 2 (right to life), imposes an investigative duty on the state. In the absence of an alternative mechanism, and in accordance with the founding principle of human rights compliance, the HIU must be able to investigate breaches of Article 3 as well as of Article 2. This provision also has the effect of enabling the HIU to investigate breaches of the investigative obligation of either Article 2 or 3 even in cases where investigation of the death or injury itself is nugatory, for example, because of the subsequent death of the identified perpetrator.

34. Sub-section (2) specifies that human rights breaches may only be investigated where such a breach is alleged in a complaint to the Police Ombudsman or is suspected by the HIU itself on reasonable grounds.

35. Sub-section (3) has the effect of placing the various elements of the investigative obligation under Articles 2 and 3 ECHR developed in the jurisprudence of the European Court of Human Rights (ECtHR) on the face of the legislation. This is important for a number of reasons. First, while the jurisprudence of the ECtHR is actually clear, various elements have 
been disputed from time to time and, for the avoidance of doubt and to reduce vexatious legal challenges, it is better to express the investigative duty clearly and explicitly in the founding legislation of the HIU. Second, there is a risk that the HIU investigative function might be interpreted narrowly on the basis of the references in paragraphs 34 and 36 SHA to 'criminal investigation' and in paragraph 34 SHA to 'evidence relevant to the identification and eventual prosecution of the perpetrator'. These references should not prevent the HIU having broader investigative functions, covering all the processes required by human rights obligations. State involvement investigations have usually gone beyond the threshold of identifying individual criminality or misconduct to findings on institutional liability, including whether the state acted unlawfully, in particular on ECHR grounds. Third, previous investigative mechanisms, particularly the Historical Enquiries Team (HET), displayed weaknesses in investigative methodology and approach and it is therefore prudent to detail the investigative process in the legislation itself.

36. Sub-section (4) makes clear, in accordance with the SHA founding principles, that stateinvolvement cases must be treated with the same rigour as any other cases. This is designed to ensure that there is no repeat of the example of the unlawful HET practice of giving more favourable treatment to suspects in state-involvement cases.

37. Sub-section (5) provides that the HIU must produce a policy which provides a definition of collusion. The sub-section is formulated to ensure that attempts to restrict the definition of 'collusion' cannot be binding on the HIU, which must ensure that its own definition incorporates a number of specific matters as well as drawing on the existing definitions developed in the Stevens and Cory collusion inquires. The definition is required as collusion is a term used in the jurisprudence of the ECtHR and part of the investigative duty codified in sub-section (3)(d).

38. The SHA (paragraph 30) specifies that the HIU will investigate 'outstanding troublesrelated deaths'. As noted above, in order to be human rights compliant, the HIU will also have to investigate breaches of the investigative obligations under Articles 2 and 3 ECHR. That still leaves a gap, however, in relation to other outstanding (not properly investigated) troubles-related serious injuries. Sub-section (6) requires the HIU to make at least an annual report to the Policing Board on whether it recommends an extension of its remit to deal with serious injury cases. The Secretary of State is given a permissive power to make relevant amendments to the Act if the HIU recommends an extension.

\section{Section 11 Cases falling within HIU's jurisdiction}

39. The SHA provides that the HIU will 'take forward outstanding cases from the HET process and the legacy work of OPONI' (paragraph 30). It provides separately in paragraph 34 that the HIU will consider all cases where the HET and PONI have not completed their work, including HET cases identified as requiring re-examination. Families can apply for new cases to be considered 'for criminal investigation' where there is new evidence 'not previously before the HET which is relevant to the identification and eventual prosecution of the perpetrator'. Section 11 seeks to bring together these examples in a legally consistent and effective manner.

40. Sub-section (1) gives jurisdiction to the HIU to investigate cases which have not been investigated by other investigating bodies or which have not been completed or which have been completed but there are good reasons to re-investigate, which explicitly include a lack of independence in the original investigation. Note that section 4 lists the organisations covered by the term 'investigating bodies' to include the PSNI (including HET), OPONI, the Royal Military Police, the Royal Ulster Constabulary and the Independent Commission for Police Complaints. Sub-section (3) makes it clear that an inquest having been held does not debar HIU from investigating a case. 
41. Sub-section (1)(b)(ii) to (iv) lays out the conditions for the HIU taking on cases which may have been formally completed. The decision in each case is that of the HIU since it is a principle of ECtHR jurisprudence that the state must carry out its investigative duties 'of its own motion' rather than in response to action by, for example, the next of kin. The first category includes cases where the HIU has reason to believe that a previous investigation was flawed in a substantive or procedural respect; the latter may include an investigation carried out by an organisation or group which lacked the requisite Article 2 independence. Sub-section (4) specifies that the 'reason to believe' may include the decision of a court or tribunal. The second category includes cases where there is new evidence, but also where there may be other reasons to investigate 'additional matters'. The third category gives the HIU the option to respond positively to well-founded requests from interested persons, who might, for example, be the next of kin, legal representatives, non-governmental organisations or officials of any public authority.

42. Sub-section (2) makes it clear that the HIU may not investigate a case which does not fall into any of the categories detailed in sub-section (1).

\section{Section 12 Priorities}

43. Section 12 provides that the prioritisation of cases should be chronological, except when the HIU believes there are special circumstances. These may well include where the next of kin or other people important to the investigation are elderly or unwell, or when it is more efficient to investigate certain cases together in the light of links between them.

44. In order to ensure transparency over the HIU's prioritisation methodology, sub-section (3) provides that the HIU must issue an annual report, or more regular reports if it wishes, to the Policing Board, providing a breakdown of both the HIU's caseload and how it has prioritised cases. Sub-section (4) makes clear that part of an investigation, such as taking a statement, can be carried out out of sequence, if needed in circumstances whereby, for example, a potential witness is elderly or in ill health.

\section{Section 13 Policing powers}

45. This section gives full policing powers to officers of the HIU. Sub-section (1) grants such officers the powers and privileges of a constable in Northern Ireland and adjacent UK waters. The sub-section of the Police (Northern Ireland) Act 2000 referred to in subsection (2) simply defines the powers of constables as those pertaining for the time being under common law or any statutory provision and defines UK territorial waters.

46. Section 66 of the Police (Northern Ireland) Act 1998 details offences such as assault on or obstruction of constables. Sub-section (3) has the effect of extending the offences concerned to an officer of the HIU.

47. Sub-section (4) makes it clear that the exclusion of police officers from certain trade union and employment rights does not apply to officers of the HIU.

48. Sub-section (5) provides that all relevant powers in the Police and Criminal Evidence (Northern Ireland) Order 1989 should be granted to officers of the HIU. It is noted that paragraph 36 SHA provides: 'In respect of its criminal investigations, the HIU will have full policing powers. In respect of the cases from PONI, the HIU will have equivalent powers to that body.' This might imply a difference in substance between HIU powers when dealing with former HET and former Police Ombudsman cases. In practice, there is little material difference between the powers of police officers and those of officers of the Police Ombudsman, but this provision ensures that officers of HIU will have all the relevant powers they need. 


\section{Section 14 Report to the Director of Public Prosecutions for Northern Ireland}

49. Sub-section (1) provides that in all cases which concern the commissioning of a crime the HIU must provide a report of its investigation to the Director of Public Prosecutions for Northern Ireland (DPPNI). This is to ensure that it is the Public Prosecution Service (PPS) not the HIU that takes the decision on whether there is sufficient evidence to mount a prosecution. When a HIU investigation does not concern the commissioning of a crime (but may cover professional misconduct), there is no prospect of prosecution and hence no role for the DPPNI.

50. Sub-section (2) provides that the DPPNI must be consulted about evidential issues and that any advice should be reflected in the prosecution report. This is designed to ensure that the expert opinion of the PPS on evidential matters is able to guide the HIU in its preparation of case details. Sub-section (3) reinforces this by providing that the HIU must include all relevant information in the prosecution report.

51. Sub-section (4) provides that the DPPNI must ensure the independence of the decisionmaking in any case by preventing the involvement of anyone who was involved in any previous consideration of the case, or in a case involving all or some of the same people.

52. Sub-section (5) is designed to make it completely clear that the fact that an alleged perpetrator was a state actor or informant is not a reason in itself to decline to prosecute in a case.

\section{Section 15 Report to deceased's family}

53. It is likely that reports to the deceased's family will be one of the main outcomes of the work of the HIU; sub-section (1) directs that this should be done in every completed investigation of a death. Sub-section (2) gives a broad definition of the term 'family.'

54. Sub-section (3) requires the HIU to give as much information as it can 'without prejudicing the administration of justice'. In practice, this is likely to mean avoiding prejudicing any potential prosecution of any person.

55. Sub-section (4) specifies certain aspects of the investigative conclusions that must be included in a family report, including whether there were any connections with other cases. These provisions are designed to ensure that victims receive clear conclusions on some of the vital issues that are likely to concern them.

\section{Section 16 Report to other victims' families}

56. People injured, or the families of those who were killed, in the same incident under investigation deserve a full report if they wish to receive one. This section ensures that the HIU will prepare such a report.

\section{Section 17 Interim reports}

57. This section gives HIU the power to issue interim reports pending the production of family reports or other victims' reports.

58. Sub-section 2 provides that the HIU will provide at least an annual report to the IRG recommending subjects for thematic investigation by the IRG and setting out the HIU's evidence base for making such recommendations. This is to fulfil the provision in paragraph 51 of the SHA that the other legacy mechanisms refer such material to the IRG. 


\section{Section 18 Public statements}

59. The SHA provides that in cases transferred from the Police Ombudsman the HIU will have the same powers as the Ombudsman would have had in such cases, which would therefore include the Ombudsman's power to issue public statements. In light of the SHA principle of fairness, we have extended this power to other HIU cases.

\section{Section 19 Non-publication of information putting lives at risk}

60. It is important to balance the family's and other victims' right to full information with restrictions on the disclosure of information that could put someone's life at risk. Subsection (1) provides that this section applies to family, other victims' and interim reports and to public statements.

61. Sub-section (2) specifies that information may be omitted from reports if its inclusion might put someone's life at risk. This is a clear test and is similar to the restriction placed on the disclosure of information by the Police Ombudsman.

62. Sub-section (3) provides that the necessary risk assessment is carried out by qualified staff of the HIU, not any outside body, and that the Director of the HIU take decisions on the necessary editing and redactions personally. This would prevent the misuse of Article 2 ECHR which has, in some instances in the past, been pleaded to redact non-sensitive material.

\section{Section 20 Other investigations}

63. This section ensures that the HIU has primacy vis-á-vis other investigative bodies in cases that come within its jurisdiction as defined in this legislation. Sub-section (1) prevents any other body from investigating a case that the HIU is investigating and sub-section (2) deals with cases involving future complaints to the Police Ombudsman about alleged past police misconduct or criminality.

\section{Section 21 International obligations}

64. Paragraphs 39 and 55 of the SHA recognise the need for cooperation with the Irish authorities in general and with respect to cross-border incidents. This section gives the Secretary of State the power to make regulations to facilitate this. The section is worded generally, rather than specifically referring to the Irish authorities, since cooperation with other states might be necessary.

65. Sub-section (1) gives the power to make relevant regulations to the Secretary of State to give effect to any international obligations entered into by the UK government or another state in respect of cross-border troubles-related deaths or breaches. The implication is that such arrangements will be made by international agreement or treaty, or by the application of any existing agreements on cooperation in, for example, criminal justice or policing.

66. Sub-section (2) defines the concept of 'cross-border' as acts or omissions connected with a death or breach which occurred or may have occurred outside the UK. Sub-section (3) singles out the possibility of making regulations to allow cooperation with or disclosure of information to specified non-UK organisations (for example, the Garda Síochána). Subsection (4) provides that regulations may modify the effect of the Act in order to facilitate cooperation. 


\section{Section 22 Disclosure to HIU}

67. Paragraph 37 of the SHA says: 'The UK Government makes clear that it will make full disclosure to the HIU.' This is an unqualified commitment; this section seeks to give practical effect to that commitment.

68. Sub-section (1) puts an unequivocal obligation on public authorities to comply with a request for information by the HIU, but also to allow the HIU to itself access any information kept by it. It also allows the HIU to set a reasonable timeframe for the request to be complied with.

69. Sub-section (2) provides that the HIU must have a unit with responsibility for accessing and processing information from other public authorities. The implication is that this unit will be security vetted and capable of handling, keeping secure and editing for onward disclosure any information, including highly classified material, which it receives or accesses, in exactly the same way as a comparable PSNI unit or the similar unit within the Police Ombudsman's office. This removes the necessity for any external oversight by any existing security or policing body or the need for prior assessment, editing or redaction.

70. Sub-section (3) overrides the named and any other enactments (for example, the Official Secrets Act 1989) and prevents them being used as an obstacle to disclosure. Subsection (4) fulfils the same function in respect of legal professional privilege except where it is claimed for advice given to an individual in a personal capacity. This provision would prevent any excuse of 'competing legal obligations' being used to frustrate disclosure to the HIU. Sub-section (6) grants the HIU a power to direct that public authorities do not alter or destroy documents or specified materials they hold which may be required for HIU investigations.

\section{Section 23 Transfer of legacy files}

71. This section deals specifically with the files of the HET and other material held by the PSNI and Police Ombudsman relating to legacy cases. Sub-section (1) says that the PSNI must 'as soon as reasonably practical' transfer such material to the HIU. In practice, this will not necessarily mean the physical movement of the material, but it must mean the transfer of 'ownership' of the files, together with the unfettered right to access them and any legal obligation that possession and control of the material may entail.

72. Sub-section (2) makes clear that the HIU will be responsible for the management of the transferred files in all respects and that they must inform the PSNI of the arrangements that they have made to accomplish this. This makes it clear that all responsibility, including onward disclosure (for example, to inquests), transfers from the PSNI to the HIU. The PSNI would have no oversight power in this respect, but the requirement to inform it of the arrangements made by the HIU would enable the latter to profit from any relevant advice from the PSNI.

73. Sub-section (3) puts a similar obligation to transfer relevant material on the Police Ombudsman.

\section{Section 24 Failure to cooperate}

74. This section makes if an offence, which might be committed by an individual, an organisation or both, to fail to comply with a duty to disclose or provide access to information for the HIU. Sub-section (2) also makes it an offence to conceal, alter or destroy information that might be relevant to a HIU investigation. 


\section{Section 25 Referrals from the DPPNI}

75. This section replicates the existing power of the DPPNI to refer cases to the PSNI for investigation to also refer cases to the HIU for investigation. Without such a power the DPPNI would only have the option of referring cases to the PSNI that in fact do not fit within its remit, but rather the remit of the HIU. The prioritisation of such cases for investigation will be a matter for the HIU.

\section{Section 26 Disclosure to the ICIR}

76. This section obliges the HIU to share on request copies of information it holds or obtains with the ICIR. Such requests will largely relate to verifying information provided to the ICIR. In order to firewall such requests and knowledge of them away from HIU investigators, the clause provides only copies are to be provided and that requests will be undertaken by the dedicated HIU disclosure unit and no other HIU staff will be made aware of them.

\section{Section 27 Duties to cooperate with the Coroner}

77. This section establishes two duties on the HIU to cooperate with the Coroner in connection with inquests into troubles-related deaths ('legacy inquests').

78. Sub-sections (1) and (2) place duties on the HIU through the HIU disclosure unit to share on request information it holds or obtains in relation to legacy inquests.

79. Sub-sections (3) and (4) relate to the HIU providing investigative services to the Coroner for legacy inquests. The Director is to establish a specialist Coroners team, separate from standard HIU investigators, for this purpose. The operational separation of the teams is both in recognition that Coroners' investigations are broader and different to criminal/professional misconduct investigations undertaken as the main work of the HIU, and also to help ensure the existence of such a role does not risk inquests being subsumed in other HIU work. Such separation is not intended to preclude cooperation between investigating teams. A specific duty is provided for to ensure such work is done in a manner compatible with ECHR rights.

\section{Section 28 Oversight by the Policing Board}

80. Section 28 is designed to make the HIU accountable to the Policing Board in a similar manner to the PSNI. The provision is similar to the provision made for the National Crime Agency in relation to its oversight by the Policing Board. In relation to duties on the HIU Director to provide information to the Board, the national security caveat placed on the PSNI Chief Constable is disapplied in relation to the HIU, given the express removal and absence of such a caveat in the SHA. Other provisions such as the HIU not having to comment on live investigations remain. As with the PSNI, this would not preclude post-investigation accountability to the Board in relation to a particular case.

\section{Section 29 Inspection of the HIU}

81. Section 29, sub-section (1), adds the HIU to the list of bodies carrying out criminal justice functions which are to be subject to inspection by the Chief Inspector of Criminal Justice for Northern Ireland (CJINI).

82. Sub-section 2 disapplies the national security caveat placed on CJINI in relation to the HIU, given the express removal and absence of such a caveat in the SHA. 
83. Sub-sections (3)-(5) add the HIU to the list of police-type bodies which can be subject to the inspections by HM Inspectors of Constabulary (HMIC). It is not intended that HMIC carry out annual or routine inspections of the HIU, given the role of CJINI who themselves can call on HMIC for assistance. Rather, the provisions in relation to HMIC empower the Policing Board to call in HMIC on an ad hoc basis to inspect a specific matter of HIU practice. HMIC can publish reports but must redact them not to endanger individuals. A national security caveat in relation to HMIC reports is disapplied, given the provisions of the SHA.

\section{Section 30 HIU complaints}

84. This section places the exercise of particular police powers of the HIU under the complaints remit of the Police Ombudsman for Northern Ireland. It is not intended that the Police Ombudsman be able to investigate complaints about all aspects of the HIU's work, some of which would be expected to be dealt with by an internal process. It is recognised that, in particular, there may be conflicts of interest if the Police Ombudsman were to review HIU investigations which had originated with the office. However, it is intended that the exercise of certain police powers by the HIU, such as those of arrest, search, seizure etc. are subject to Ombudsman oversight. In a manner similar to the existing provisions for the Police Ombudsman for immigration officers, the clause provides that a memorandum of understanding be developed by the Ombudsman and HIU, and approved by the Policing Board, which will specify the range of policing powers exercised by the HIU which will be subject to the Ombudsman's complaints remit.

\section{Section 31 Finance of external bodies supporting HIU functions}

85. This section is intended to ensure the above oversight and inspection bodies are not precluded from their role in relation to the HIU, which is additional to existing functions, by lack of resourcing. In order to ensure independence and in recognition that the HIU functions constitute an international obligation, this section, as with the HIU, provides that such functions are resourced from the UK Treasury Consolidated Fund.

\section{PART 3 INDEPENDENT COMMISSION ON INFORMATION RETRIEVAL}

86. Paragraph 41 of the SHA states:

A new body, which will respect the sovereign integrity of each jurisdiction, will be established by the UK and Irish Governments, called the Independent Commission on Information Retrieval (ICIR), building on the precedent provided by the Independent Commission on the Location of Victims' Remains. The objective of the ICIR will be to enable victims and survivors to seek and privately receive information about the (Troubles-related) deaths of their next of kin.

This Part seeks to implement that intention.

87. Since the establishment of this body is envisaged as a joint enterprise by the UK and Irish governments, it will require an Agreement, with the status of an international treaty, between the UK and Ireland. The suggested text of such an Agreement is included at Schedule 2; the suggested UK legislation required to implement it is included in this Part. Legislation will also be required in Ireland to implement the agreement.

88. The ICIR, as described in the SHA, will be a novel institution with many complexities necessarily arising in its work and many sensitive issues will need to be negotiated. Perhaps in recognition of this, paragraph 50 of the SHA includes the additional principles of independence and rigour which are to apply to the operations of the ICIR. The drafting 
committee is of the view that the full nature and method of operation of the ICIR will have to be expressed at four levels: the Agreement between the UK and Ireland, primary legislation in the UK and Ireland, regulations that may be made by statutory instrument, and a statutory Code of Practice or guidance. These explanatory notes will endeavour to indicate where the drafting committee feels issues should be dealt with by subordinate forms of regulation.

\section{Section 32 Establishment ICIR}

89. Sub-section (1) refers to the ICIR as a body established pursuant to the Agreement ('the Founding Agreement') between the UK and Ireland and describes its objective as laid out in the SHA. Sub-section (2) notes that the text of the Agreement is to be found in Schedule 2.

90. Sub-section (3) puts an obligation on the Secretary of State and the First and Deputy First Ministers to implement in practice the provisions of the Agreement and in particular to ensure that the ICIR has independence and autonomy, as detailed in the Agreement.

91. Sub-sections (4) and (5) deal with the period of existence of the ICIR. In the first place it shall exist for five years from the coming into force of the founding legislation but the Secretary of State, after consulting the Irish Minister for Justice and Equality, may by statutory instrument extend or revive the life of the body.

92. Sub-section (6) relates to the fate of the ICIR's archives. This issue was not addressed in the SHA. The drafting committee considered requiring that the archives be destroyed upon completion of the ICIR's work, as we were mindful that a guarantee to do so could give reassurance to possible information providers. However, the Model Bill instead makes arrangements for the archives to be held securely and confidentially for 50 years in a manner that is to be determined by the Commission. We felt that this was necessary as the ICIR has the potential to gather a wealth of information that may be useful for understanding Northern Ireland's history in generations to come. The Model Bill further stipulates that penalties incumbent on ICIR Commissioners and staff regarding the disclosure of confidential information remain in effect throughout this period.

\section{Section 33 Capacity, immunities and finance}

93. Sub-sections (1) to (3) deal with the establishment of the ICIR as a corporate body and give a power to the Secretary of State to regulate to grant privileges and immunities relevant to an international body and to its functions. The referenced Schedules of the International Organisations Act 1968 deal with possible exemptions from tax, rates and excise duties and other legal obligations of various kinds. Only some of these privileges and immunities are likely to be relevant to the ICIR. However, the most relevant privilege is immunity from suit and legal process'. These sections therefore give the Secretary of State power to implement paragraph 47 of the SHA which says: 'The ICIR will be given the immunities and privileges of an international body and would not be subject to judicial review, Freedom of Information, Data Protection and National Archives legislation, in either jurisdiction.'

94. Sub-section (4) obliges the Secretary of State to fund the operations of the ICIR in such a way as to guarantee the independence of the body as provided for in the Founding Agreement. Sub-section (5) provides that the monies are to be paid out of the Consolidated Fund; that is from central UK funds decided by parliamentary vote. 


\section{Section 34 'Victims and survivors'}

95. The SHA uses the terms 'victims and survivors' and 'next of kin' of those who suffered troubles-related deaths to identify those who might seek information from the ICIR. For the avoidance of doubt, and to give the ICIR an element of discretion, this section defines such people ('victims') as the family of those who suffered troubles-related deaths and gives a broad definition of family with the ICIR able to include persons who it 'thinks had a relationship of a family character with the deceased'.

\section{Section 35 The work of the ICIR}

96. The overall purpose of this section is to oblige the Secretary of State to make regulations about aspects of the work of the ICIR either specified in the sub-sections or contained in the Founding Agreement which will provide the legal framework within which it can carry out its work. As noted in paragraph 88 above, the complexity of the work of the ICIR will be such that it would be more appropriate for the details of this legal framework to be provided in subordinate, rather than primary legislation.

97. Sub-section (1) specifies that immunities or other protection must be given to people who communicate or cooperate with the ICIR. These should be similar to those granted to people who cooperate with the Independent Commission on the Location of Victims' Remains.

98. Sub-section (2) specifies that regulations must compel public authorities to provide information to the ICIR. The body will, of course, be attempting to access information also from non-state individuals or bodies, but it is not possible to compel unknown individuals or groupings to provide information by law. It is likely that the means of outreach and the protocols for information-gathering from private individuals or entities will be contained in a Code of Practice.

99. Sub-sections (3) and (4) provide for the implementation of provisions of the SHA and the proposed Founding Agreement relating to the confidentiality and inadmissibility in legal proceedings of information provided to the ICIR.

100. Sub-section (5) specifies that regulations must prohibit knowingly giving false information to the ICIR, obstructing its work (by, for example, destroying documents) and any disclosure of information by members or staff of the Commission. Such prohibition would implicitly create offences, specifically permitted by sub-section (6)(c). It is accepted by the drafting committee that taking civil or criminal proceedings against someone who has, for example, provided false information to the ICIR, but in confidence, might be difficult or impossible. This is an issue that should be given greater consideration when drafting the secondary legislation and Code of Practice.

101. Sub-section (7) makes provision for the Code of Practice discussed above.

\section{PART 4 IMPLEMENTATION AND RECONCILIATION GROUP}

\section{Overview}

102. Paragraph 51 of the SHA states:

An Implementation and Reconciliation Group (IRG) will be established to oversee themes, archives and information recovery. After 5 years a report on themes will be commissioned by the IRG from independent academic experts. Any potential evidence base for patterns and themes should be referred to the IRG from any of the legacy mechanisms, who may comment on the level of 
cooperation received, for the IRG's analysis and assessment. This process should be conducted with sensitivity and rigorous intellectual integrity, devoid of any political interference.

103. The SHA also states that:

- promoting reconciliation will underlie all the work of the IRG (paragraph 52);

- the IRG will encourage and support other initiatives that contribute to reconciliation, better understanding of the past and reducing sectarianism (paragraph 52);

- in the context of the work of the IRG, the UK and Irish governments will consider statements of acknowledgment and would expect others to do the same (paragraph 53);

- the IRG will be 11-strong, with further provision on appointments (paragraph 54).

\section{The case for statutory provision}

104. There is a strong case for giving the IRG a statutory base, instead of leaving its establishment and work to be determined simply by administrative or political agreement:

- Statutory provision will give the IRG a firmer and better defined basis for its existence. It will give the IRG more weight;

- It will ensure that the IRG functions properly and fulfils its mandate in accordance with the SHA. It will make the IRG less vulnerable to political dispute and will enhance the process of reconciliation;

- The IRG has oversight of matters such as archives and information recovery, which themselves will have a statutory basis. Statutory provision will help define the relations between all four new legacy bodies (HIU, ICIR, IRG and $\mathrm{OHA}$;

- Statutory provision would fix the procedures for the report on themes and compilation of the evidence base;

- It would guarantee that the IRG would continue to function for the period after the HIU and ICIR had been wound up and before the report on themes was completed.

\section{Structure of Part 4}

105. This Part of the Bill is divided into five headings:

- Definitions (section 36);

- Establishment, nature, status, organisation and governance (sections 37-45);

- Objective and functions (sections 46-47);

- Relationship with other bodies (section 48);

- Report on themes and the evidence base (sections 49-50).

\section{Particular questions}

106. The drafting committee has sought to address the following particular questions:

- the appointment and tenure of the members of the IRG;

- the duration of the IRG; 
- the nature of the IRG's oversight of themes, archives and information recovery;

- the extent of the IRG's work on outreach, reconciliation and statements of acknowledgment;

- the handling of the report on themes, including its timing;

- the compilation of the evidence base.

\section{Section 36 Definitions relevant to the IRG}

107. Section 36 provides a list of definitions relevant to the IRG. When the relationship between the various parts of the Bill is finally determined, some of these definitions might fit better in section 69 (interpretation) applying to the Bill as a whole. Particular definitions are discussed further below in the context of the provisions to which they relate.

\section{Section 37 Establishment of the IRG}

108. Sub-section (1) provides for the establishment of the IRG as a body corporate. The arguments for a statutory body have been set out in paragraph 104 above.

109. Sub-section (2) provides that the members of the IRG shall be appointed by the First Minister and Deputy First Minister, acting jointly, as soon as practicable after the entry into force of this section and in accordance with nominations under this section. The SHA does not give the Secretary of State a role in the nomination or appointment procedure, either of the Chair or other members, so the Bill has excluded the Secretary of State entirely from the appointment procedures outlined in sub-sections (2) to (8).

110. Sub-section (3) specifies that the IRG shall consist of 11 members in accordance with paragraph 54 SHA (first sentence).

111. Sub-section (4) provides that First Minister and Deputy First Minister shall nominate the Chair in accordance with paragraph 54 (third sentence). As in the SHA, the sub-section specifies that the Chair shall be independent and of international standing.

112. Sub-section (5) follows the nomination procedures for other members of the IRG outlined in paragraph 54 (fourth sentence).

113. Sub-section (6) bars from appointment publicly elected representatives, following paragraph 54 (second sentence).

114. Sub-section (7) encourages those making nominations to the IRG to work together to ensure gender balance. This reflects a principle which the drafting committee has sought to apply to all the new legacy bodies, for example, by section $5(6)$ in the case of the HIU and paragraph 5(9) of the Founding Agreement in the case of the ICIR.

115. Sub-section (8) specifies the qualities and experience required for members of the IRG and the requirement to act independently and impartially, free from any political interference. The criteria are similar to those required for Commissioners of the ICIR by paragraph 5(8) of the proposed Founding Agreement.

\section{Section 38 Chair of the IRG}

116. This provides for the appointment of the Chair and the Chair's replacement in the event that he or she resigns or is not able, willing or fit to perform the functions of office. It is similar to other provisions for office-holders in the case of other institutions, for example, the Commissioners of the ICIR under paragraph 6 of the Founding Agreement. 


\section{Section 39 Other members of the IRG}

117. Sub-section (1) suggests a term of three years for members of the IRG. This is not specified in the SHA. The argument for three years is that this allows the possibility of both change and renewal of members of the IRG a reasonable period after its establishment (three years), but before a decision is taken on the report on themes (at five years). The likely life of the IRG is about nine years, allowing for completion and publication of the report on themes: see section 49(5) and (6). A tenure of three years would fit with this cycle, allowing two points of renewal or review. An alternative might be appointment for the full life of the IRG, but this might make membership of the IRG too static.

118. Sub-section (2) allows for the situation where the IRG's work is completed while a part of a three-year period of tenure of the members remains outstanding. It provides that the appointment of the members lapses with the completion of the IRG's work.

119. Sub-sections (3) to (6) are provisions parallel to section 38(2) to (5), dealing with cases where a member of the IRG resigns or is not able, willing or fit to perform the functions of office.

\section{Section 40 Remuneration and allowances}

120. Section 40 enables the Chair, in consultation with the First Minister and Deputy First Minister, to determine the terms of appointment of members including, in particular, whether members shall work for the IRG on a full-time or part-time basis (according to the requirements of the IRG from time to time). The requirements of the IRG may vary, but it is likely to be sufficient for the members to work part-time.

\section{Section 41 Secretariat}

121. The IRG is likely to have a lighter burden of work than the HIU, ICIR and OHA, but will still require administrative support for its work on reconciliation, themes and acknowledgment and for its oversight duties. Section 41 therefore proposes the establishment of a Secretariat, with similar provisions to the other institutions.

\section{Section 42 Funding}

122. This section guarantees continued funding for the IRG, including its staff and administration, out of the Consolidated Fund.

\section{Section 43 Annual report}

123. The IRG would account for its work by means of an annual report of its activities.

124. Sub-section (2)(a) specifies that the report may include recommendations to groups and bodies in Northern Ireland, including the legacy institutions, and to the two governments for further work on implementation and reconciliation within the scope of its mandate. This reflects the IRG's broader remit of promoting and supporting reconciliation under paragraph 52 SHA.

125. Sub-section (2)(b) specifies that the report may comment on the level of cooperation between the legacy institutions and others. This picks up the reference to such cooperation in paragraph 51 SHA.

\section{Section 44 Governance}

126. The Bill cannot lay down detailed provisions of governance but, with a body 11 strong and drawn from various political groupings, it ought to provide some basic principles of 
decision-making. Hence the draft suggests that ordinary decisions should be taken by a simple majority, but that the decision to commission the report on themes should be approved by at least seven members.

\section{Section 45 Duration}

127. This section, taken together with section 46(b) and section 49(5) and (6), provides a timetable for the IRG's work, based on the report on themes. Section 46(b) reflects the statement in paragraph 51 SHA that this report will be commissioned after five years. It suggests that this five-year period should run not from the date of the IRG's establishment but from the date of the SHA. Time needs to be allowed for writing and completion of the report, for which section 49(5) suggests three years. The aim should be for the IRG to publish the report as soon as possible thereafter and, for this, section 49(6) allows a maximum of one year.

128. Publication of the report might provide an occasion to consider statements of acknowledgment and to recommend further activities of outreach and reconciliation, reflected in section 49(7) - see below. That should mark the completion of the IRG's work and, on this basis, six months might be sufficient to wind up the IRG after completion of the report on themes. This is therefore what section 45(1) proposes.

129. There are, however, obvious uncertainties. It is difficult to tell at this stage how precisely the IRG will fulfil its mandate and how in particular it will deal with the challenges outlined in paragraph 52 SHA. Section 45(2) therefore allows the Secretary of State by order to extend the life of the IRG.

\section{Section 46 Objectives and functions}

130. This brings together the objectives and functions of the IRG as outlined in paragraphs 51-53 SHA. Although paragraph 53 does not attribute a specific role for the IRG in statements of acknowledgement, these are to be considered 'in the context of the IRG'. Section 46(d) therefore provides that the IRG should encourage such statements and (in line with paragraph 53) not just from the two governments but from others. The timing aspects of section 46(b) have been referred to above.

\section{Section 47 Exercise of functions}

131. Particularly in view of its oversight duties, the IRG should have full independence and operational autonomy. Although the members of the IRG are nominated by the political parties, it is important that the IRG - as the other legacy bodies - operates as an independent body and complies with the SHA founding principles (for which see paragraph 21 SHA and section 1(3) of the Bill). Section 47(2) incorporates the final sentence of paragraph 51 SHA on the conduct of the report on themes. Section 47(3) allows the IRG to adopt a Code of Practice, with which it must comply in the conduct of its proceedings.

\section{Section 48 Relationship with other bodies}

132. This section gives some specifics to the IRG's oversight duties in respect of the ICIR and $\mathrm{OHA}$, but deliberately does not prescribe these in detail. The drafting committee believes that the IRG's oversight of the ICIR and OHA should be 'light touch', allowing these institutions generally to get on with their work. Section 48(1) therefore mirrors provisions elsewhere in the Bill for the ICIR and OHA to provide annual reports to the IRG (paragraphs 4(j) and 10(4) of the Founding Agreement in Schedule 2 and section 63(2)(m)). 
And section 48(2) enables the IRG to 'make recommendations' (but no stronger) to the ICIR and OHA as to their future activities.

\section{Section 49 Report on themes}

133. Section 49 describes the procedure and conditions for the report on themes. Section 46(b) previously states that this should be commissioned five years after the date of publication of the SHA. The provision in section 49(1) that the IRG shall commission the report on themes picks up this reference.

134. Paragraph 51 SHA states that the report should be commissioned 'from independent academic experts'. This is reflected in section 49(1) and section 49(3). The latter provision, which describes the necessary qualities of the experts, also draws on wording from other requirements for the process in the SHA (sensitivity, rigorous intellectual integrity and devoid of any political interference).

135. Section 49(2) makes clear that it is the IRG which decides the themes to be included in the report. This is consistent with paragraph $51 \mathrm{SHA}$, which also provides, however, that any of the legacy mechanisms should be able to refer to the IRG any potential evidence base for patterns and themes. In practice, the choice of themes is likely to be the culmination of an evolving process over the first five years, as the evidence base is developed. It would therefore be natural for the IRG to consult the other legacy mechanisms before it finally decides the themes to be included in the report. The drafting committee suggests, also in section 49(2)(b), that the IRG should consult victims and organisations representing their interests.

136. Section 49(4) recognises that different experts might be required to work on different themes and the structure of the overall 'report on themes' might need to be flexible to accommodate separate studies on separate themes. Sub-sections 49(5) to 49(7) have already been covered in the commentary above.

\section{Section 50 Evidence base}

137. This section provides guidance for compilation of the evidence base. As noted above, paragraph 51 states only that 'any potential evidence base for patterns and themes should be referred to the IRG from any of the legacy mechanisms ... for the IRG's analysis and assessment'. This recognises that the IRG could not commission the report on themes, nor could the academic experts after five years compile the report, unless in the first five years a proper evidence base had been established. Section 50(1) therefore enables the IRG to compile the evidence base to facilitate the report on themes.

138. Section 50(2) provides for the IRG to engage suitably qualified and vetted analysts and experts. The vetting requirement follows from section 50(4), which envisages that the evidence base would include confidential material. Without access to confidential material, the report on themes is unlikely to be able to add value to existing publications or achieve more than a normal open-source research project. Section 50(5) enables the legacy mechanisms to pass such confidential material to the IRG's analysts and experts subject to conditions which they might specify. Section 50(6) allows the possibility that the IRG would also receive information from other public bodies. These provisions stop short of requiring other institutions to provide material to the IRG. But it is important that this should not be used to thwart the IRG's work. Hence section 50(7) provides that the two governments should facilitate the provision of information relevant to the evidence base. 


\section{PART 5 ORAL HISTORY ARCHIVE}

\section{Section 51 Definitions}

139. This section provides a list of definitions applicable to this Part. As with section 36 in respect of Part 4 (the IRG), some definitions might be transferrable to a definitions section applicable to the whole Bill.

140. Most of the definitions are straightforward, but it should be noted that 'collectors' includes interviewers collecting new material as well as those tasked with identifying existing material which may be deposited with the Archive. Likewise, 'contributors' includes those interviewed for existing projects which may now be deposited with the Archive as well as those contributing new material.

141. Sub-section (d) specifies that 'oral history material' includes recordings of interviews (both audio and audio-visual) and related documentation and artefacts. The latter may include transcripts, consent forms, project summaries and descriptions, interview schedules or indicative topics, metadata, catalogues to collections, biographical cameos for interviewees, photographs of interviewees, creative works and other materials that support or inform recorded interviews (e.g. press-cuttings, films, photographs, unpublished manuscripts).

\section{Section 52 Establishment}

142. This part seeks to implement para 22 of the SHA which states: 'The Executive will, by 2016, establish an Oral History Archive to provide a central place for people from all backgrounds (and from throughout the UK and Ireland) to share experiences and narratives related to the Troubles.'

143. In view of the significant sensitivities and challenges arising, the drafting committee considers it appropriate that this resource be established by the First Minister and Deputy First Minister, acting jointly.

144. Sub-section 3 specifies that the First Minister and Deputy First Minister, acting jointly, shall determine the location of the OHA. It is envisaged that the Archive will, for the most part, be accessible online. A 'central place' could thus be envisaged partly as a cyber-space, but an appropriate central physical space in which people can listen to recordings and access supporting documentation should also be provided.

\section{Section 53 Principles of operation}

145. This section obligates the First Minister and Deputy First Minister, acting jointly, to give force to paragraph 24 of the SHA which states that: 'The Archive will be independent and free from political interference.' This is key to the success of the OHA. If the Archive is to attract the participation and support of 'people from all backgrounds and from throughout the UK and Ireland', it must be safeguarded against manipulation by vested interests. As noted in section 57(7), those tasked with running the Archive must be impartial and perceived to be impartial by potential contributors and stakeholders. It is also essential that they do not have financial, professional or other interests that are reasonably likely to conflict with the exercise of their functions.

146. Sub-section (2) underlines the importance of consistent adherence to the founding principles. 


\section{Section 54 Code of practice}

147. Sub-section (1) provides for the establishment of a non-statutory Code of Practice to provide guidance on the work of the OHA.

148. Sub-section (2) notes that the Code of Practice must include a comprehensive Code of Ethics designed primarily to safeguard the rights and needs of contributors. This will acknowledge and outline the specific measures required to facilitate contributions from victims and survivors (including, for example, advocate-counsellor assistance where appropriate). The Code of Practice will obligate the OHA to take reasonable steps to protect information that appears to be sensitive or confidential, within the limits of the law. This includes anticipation and provisions for the medium to long-term fate of data. The Code will also outline the importance of ensuring that collectors and contributors are aware of the legal implications of acquiring, processing and storing oral history material.

\section{Section 55 Capacity}

149. This section stipulates that the Secretary of State may by regulations confer on the OHA the legal capacities of a body corporate. The drafting committee believes that this is the legal construction most likely to facilitate the independence of the OHA.

\section{Section 56 Immunity from suit}

150. Paragraph 23 of the SHA states that 'consideration will be given to protecting contributors, and the body itself, from defamation claims'. The drafting committee has considered the full range of claims that could potentially arise in relation to the exercise of the functions of the OHA and proposes in sub-section (1) to provide immunity from suit for staff and agents of the OHA in respect of all acts or omissions occurring in good faith in the execution of functions in connection with the OHA.

151. In relation to defamation claims, it is suggested that qualified privilege under Schedule 1 of the Defamation Act 1996 should attach both to statements made by contributors by way of contribution to the OHA and records or publications of such statements by the OHA.

\section{Section 57 Appointment of Executive Board and Advisory Board}

152. The governance structure for the OHA must enable it to function in a manner that is 'independent and free from political interference' (paragraph $24 \mathrm{SHA}$ ). It should reflect the protean nature of oral history and facilitate the Archive in its 'attempt to draw together and work with existing oral history projects' (paragraph 22 SHA). Developing relationships with existing projects presents numerous challenges. Existing projects fear that the proposed OHA could become the oral history archive of the Troubles, implicitly threatening or diminishing the contribution that they have made or continue to make. It is vital that the proposed OHA acknowledges and draws on the considerable expertise, experience and oral history material that already exists and that it seeks to work with existing projects in a spirit of mutually beneficial partnership (see section 63 (3)).

153. The Bill does not propose detailed and prescriptive provisions for governance but the drafting committee considers that an Executive Board consisting of three Directors assisted by an Advisory Board should enable the OHA to function optimally.

154. Section (3) stipulates that the Chair of the Executive Board and one other executive Director shall be appointed by the First and Deputy First Minister, acting jointly. In keeping with the remit outlined in the SHA (paragraph 22) one other Executive Director shall be appointed by the Secretary of State, in consultation with the government of the Republic of Ireland. 
155. The role of the Advisory Board will be critically important. Sub-section (6) states that this Board shall consist of seven members. The Chair shall be appointed by the First and Deputy First Minister, acting jointly, in consultation with the two governments; three members shall be appointed by the First Minister and Deputy First Minister; one member shall be appointed by the Secretary of State; and one member shall be appointed by the Secretary of State, in consultation with the government of the Republic of Ireland.

156. Sub-section (6)(3) states that one member shall be the Deputy Keeper of the Public Records Office of Northern Ireland (PRONI) ex officio. This acknowledges the expertise of PRONI in digitising, cataloguing, preserving and providing access to official documentary records and the potential that exists for the sharing of resources, facilities and knowledge.

157. Sub-section (7) outlines the skills and attributes necessary for appointment to both the Executive Board and the Advisory Board. Appointees are likely to include representatives of existing oral history projects and networks. Sub-section (8) emphasises the importance of ensuring a gender balance across the governance structure.

\section{Section 58 Tenure of Executive Directors}

158. This section sets out the appointment and tenure for the Executive Directors of the OHA. Sub-section (2) stipulates that appointment is for five years and may be renewed, subject to the stated provisions.

\section{Section 59 Tenure of members of Advisory Board}

159. This section sets out the appointment and tenure for the Advisory Board members. Subsection (2) states that appointment is for five years and may be renewed, subject to the stated provisions.

\section{Section 60 Secretariat}

160. The work of identifying, facilitating, recording, processing, preserving and providing access to oral history material is time-consuming and demands a range of practical, technical and professional skills. Section 60 thus provides for the establishment of a Secretariat to provide research, archival, interviewing and other professional and administrative support to the OHA. Sub-section (2) stipulates that the Directors shall appoint the staff of the OHA. The relevant skills and expertise are referred to in sub-section (3). These include the same qualities and attributes required of Executive and Advisory Board members in section 57(7). Sub-section (3) underlines the potential for memory to provoke psychosocial and traumatic harm and also the need for gender sensitivity in exercising judgements about the functions and development of the Archive.

161. Sub-section (4) notes that staff may be (but need not be) appointed on secondment from a public authority, including PRONI.

\section{Section 61 Remuneration and allowances}

162. This section stipulates the First and Deputy First Ministers, acting jointly, shall specify the appropriate remuneration and allowances for the Executive Directors. The Executive Directors will, in turn, determine the remuneration and allowances of staff.

\section{Section 62 Funding}

163. This section guarantees adequate funding (including payments and expenses to staff and Advisory Board members and the provision of appropriate premises and facilities) for the OHA out of the Consolidated Fund. It also provides for publication of a statement that details transparent accounting procedures and the operational independence of the OHA. 
164. These provisions stop short of specifying the precise funding arrangements beyond the establishment costs drawn from the Consolidated Fund. It is, however, vital that the OHA is funded beyond the five-year period envisaged for other mechanisms. Providing an adequately resourced central repository for existing and new oral history material related to the Troubles is key to the success of the OHA. Here it can build on the work of Incore's Accounts of the Conflict project and help to bridge a critical gap between the impulse to collect and the obligation to preserve our shared cultural heritage. Collecting, safeguarding and providing access to oral history material in the medium to long term is central to the legal and ethical framework that will be embodied in the Code of Practice and to the principle of 'promoting reconciliation'. It will enable victims and survivors to engage with the Archive at a time and place that best suits their needs, enable contributors to renegotiate memories, and facilitate intergenerational understanding and learning.

165. It is intended that contributors will be invited to assign copyright in their interviews to the OHA and that the OHA will be equipped with the resources necessary to enable it to attend to long-term storage and preservation of oral history material. It may alternatively enter into negotiations with existing repositories with regard to the sharing of facilities and resources for the purposes of long-term preservation. Consent and copyright waivers will be styled accordingly.

\section{Section 63 The work of the OHA}

166. This substantive section outlines the specific work of the OHA. Sub-section (1) sets out the two core aims: to collect new oral history material from people from all backgrounds throughout the UK and Ireland and to seek to draw together and work with existing oral history projects.

167. Sub-section (2) outlines the necessary steps to achieve these aims. They are designed to meet and mitigate a number of interrelated challenges and risks. Firstly, buy-in from the necessary range of contributors and stakeholders cannot be taken for granted. Secondly, there is a real danger that the OHA could (from the outset) be manipulated by vested interests. It is therefore imperative that the Archive does not rely on a process of voluntary self-selection and instead engages in comprehensive outreach and engagement.

168. Comprehensive outreach and engagement is also necessary to identify and acknowledge the good work that has been done and that continues to be done by existing oral history projects and to avoid duplication of effort.

169. It is by no means easy or straightforward to identify themes that will 'promote reconciliation' and 'acknowledge and address the suffering of victims and survivors'. It is equally challenging to identify and collect experiences and narratives in a manner that is 'balanced' and 'proportionate'. Promoting reconciliation may demand that we go beyond narrow political definitions and terms of reference and think creatively and flexibly about ways and means of capturing perspectives that either have not been heard or that need to be heard in the interests of real and lasting peace and reconciliation. The work of the Advisory Board will be key in helping to draw out these challenges and dilemmas. Sub-section (2)(b) notes the importance also of consulting with international stakeholders who have encountered similar challenges in transitional and post-conflict settings, and with the IRG.

170. Sub-section (2)(e) provides for a central training programme designed to enable people from across the UK and Ireland to collect interviews in their communities and organisations for deposit with the OHA and to ensure that collectors comply with the Code of Practice. This is intended as a cost-effective means of enabling the OHA to operate with as much flexibility as possible, and with minimal organisational structure and 
constraint. A centralised training programme could, we suggest, borrow from the success of commercial franchise operations. It would ensure that a wide range of organisations from throughout the UK and Ireland are facilitated in the creation of appropriate oral history material and that their efforts and zeal are given the necessary direction and quality control. This model is underscored by the principle of subsidiarity - the belief that the central OHA should not perform tasks more appropriately undertaken by those closest to the ground.

171. Sub-sections $(2)(\mathrm{f}-\mathrm{j})$ provide for the conduct, processing and preservation of recordings and relevant supporting data. They emphasise in particular that all reasonable steps must be taken to safeguard contributions which are to be kept confidential.

172. Sub-sections (2)(k) and (2)(l) point to the fact that material accruing to the OHA is primarily intended for immediate public access. To facilitate the sharing of experiences and narratives and confrontation with 'other voices' the OHA must prepare and make available catalogues of oral history material and facilitate free public access - both online and at a designated physical location.

173. Sub-section $(2)(\mathrm{m})$ requires the OHA to make progress reports to the IRG at least annually. These should include reference to categories of interviewees that have engaged with or declined to engage with the Archive. They should also outline the process of identifying themes and topics for interviews. Preliminary analysis of the interview material may help to identify themes for further consideration by the IRG.

174. Sub-section (3) acknowledges the considerable challenges (practical, ethical and legal) of attempting to 'draw together and work with existing oral history projects' (paragraph 22 SHA). Sub-section (3)(c) thus suggests that a designated member of the Secretariat should lead on this aspect of the work. As noted in paragraph 152 above, the relationship between the OHA and existing projects and networks should be mutually beneficial. The OHA could, for example, address a critical gap in terms of providing adequate resources to digitise and safeguard oral history material into the future. Training opportunities could also benefit existing oral history projects. The precise arrangements governing the relationship between the OHA and existing oral history projects (e.g. deposit of existing collections or deposit of new material collected under the auspices of the OHA in line with its Code of Practice) must be determined on a case-by-case basis after due consultation and agreement.

175. Sub-section (3) emphasises the importance of avoiding duplication of effort and/or diminishing the good work that has gone before. This extends both to existing projects and to networks such as the Healing Through Remembering Storytelling Network. The proposed strategy of outreach to existing projects and stakeholders is designed to ensure that public monies are deployed wisely and prudently in pursuit of the founding principles and that relations between the OHA and existing projects and networks are mutually beneficial and supportive.

176. Sub-section (3)(g) states that, where existing projects choose to deposit material (whether in duplicate or in toto) with the OHA, the terms of the original deposit will to the fullest extent possible be respected.

\section{Section 64 Arrangements with PRONI}

177. This section acknowledges that PRONI has significant expertise in relation to the digitisation, cataloguing and preservation of official records and as such may wish to share facilities, equipment and expertise. 


\section{Section 65 Engagement with contributors}

178. This section describes the nature of the relationship between the OHA and contributors. It stipulates that engagement with the OHA is voluntary and that contributors can withdraw from the process at any time. It also obligates the OHA to take all reasonable steps to ensure that contributors appreciate in advance the potential legal consequences of engaging with the OHA. Should contributors provide sensitive or confidential data, the OHA shall take all necessary steps to avoid identifying them prematurely. It will also provide contributors, wherever possible, with a copy of the final version of the oral history material which they have contributed. This may exclude material that the $\mathrm{OHA}$ and/or the contributor hav deemed unfit for immediate publication.

\section{Section 66 Obtaining and holding information}

179. This section acknowledges the risks associated with the OHA taking possession of information relating to specific offences or alleged offences that have not been fully dealt with by the courts of all relevant jurisdictions and obligates the OHA to avoid such a situation arising.

180. Sub-section (2) acknowledges the risk associated with the leakage of information that could breach a person's rights under the ECHR and thus requires that the OHA processes and stores data in a suitably secure manner.

\section{Section 67 Publication of information}

181. This section arises from paragraph 23 of the SHA which states that: 'The Archive will bring forward proposals on the circumstances and timing of contributions being made public.' Sub-section (1) notes that the primary intention of the OHA is to make oral history material publicly available. Subsequent sub-sections detail the necessary exceptions to this rule.

182. Sub-section (2) points to the necessity of subjecting all material accepted by the OHA to a sensitivity review to establish whether it should be kept confidential for a specified period. Sub-section (3) notes that a contribution may be so embargoed if a contributor so requests or, in the absence of such a request, the OHA considers that publication would present a substantive risk to an individual.

183. Sub-section (4) notes that decisions as to the circumstances and timing of contributions being made public will be arrived at in consultation with contributors. Sub-section (5) notes, however, that there may be circumstances in which the OHA must overrule the stated preference of a contributor. As noted in sub-section (6), such decisions will be arrived at after due consideration of the contributor's wishes and in consultation with properly trained staff and international best practice.

184. Sub-section (7) suggests that a contribution will only be kept confidential for a period longer than 30 years if the OHA is satisfied that publication of the contribution or relevant part thereof would continue to present a substantive risk to an individual.

185. Sub-section (8) acknowledges that many contributors may be reticent about contributing 'experiences and narratives related to the Troubles' and that such accounts are likely to include reference to issues of considerable local, familial or public sensitivity. In order to protect and offer reassurance to contributors the drafting committee thinks it advisable to disapply the Data Protection Acts and the Freedom of Information Act 2000 to all contributions until such times as a contribution has been finalised by the OHA and thereafter to any contribution which the OHA decides to keep confidential in accordance with this section. 
186. Sub-section (9) specifies that in the unlikely event of a court order demanding that the OHA disclose or provide access to a contribution, the OHA must immediately notify the relevant contributor (or next of kin) and provide them with an opportunity to make representations to the relevant authority. This might include demonstration of the steps taken to ensure that the specified contribution does not include information about specific offences or alleged offences that have not been fully dealt with by the courts of all relevant jurisdictions.

187. Sub-section (10) provides further clarification on the meaning in this section of a 'contribution' and 'a substantive risk to an individual'.

\section{Section 68 Arrangements with the Republic of Ireland}

188. This section acknowledges the obligation in paragraph $22 \mathrm{SHA}$ to facilitate contributions from 'throughout the UK and Ireland' and suggests that the OHA should make such arrangements with bodies (oral history networks, archives, libraries and other such organisations) as it sees fit.

189. Sub-section 2 notes that the Northern Ireland Executive and the Secretary of State shall, as appropriate, facilitate this process, if necessary by the conclusion of arrangements between the two governments (including, if necessary, supporting legislation)

\section{PART 6 GENERAL}

190. This Part deals with interpretation of various terms and the procedure for the adoption of regulations and is self-explanatory.

\section{SCHEDULE 2 TEXT OF THE AGREEMENT BETWEEN THE UNITED KINGDOM AND IRELAND ON THE ESTABLISHMENT OF THE INDEPENDENT COMMISSION ON INFORMATION RETRIEVAL}

\section{Paragraphs 1 to 3 Establishment, objective and guiding principles}

191. These paragraphs agree the establishment of the ICIR, specify its objective as set out in the SHA and subject its operations to the guiding principles set out in the SHA. Paragraph 50 of the SHA includes additional principles, specific to the ICIR, of independence and rigour.

\section{Paragraph 4 Specific functions}

192. Paragraph (4) lists the specific functions of the ICIR which are, in the opinion of the drafting committee, the minimum necessary if it is in fact to carry out the intentions of the SHA. As such, it is important that these functions be listed in the Agreement between the UK and Ireland which will provide the foundation stone of the ICIR. Although some aspects are elaborated upon in subsequent paragraphs, further detailed guidance on the complex and sensitive work that will be necessary if the ICIR is to be effective should be given in the Code of Practice.

193. Sub-paragraph (a) deals with the preparation of a Code of Practice. Some of the points that might be included in a Code of Practice are the need for a strategic communication plan, the need to work across the UK and Ireland and with, for example, conflict-affected communities, community groups, religious organisations, ex-prisoners' associations, current and former security force personnel and other groups, political parties, women's organisations and through social media, websites and public advertisements. Similar details will be required for other functions, although the nature of work with victims, reports to 
victims and the collection, holding and use of information are prescribed in somewhat more detail in subsequent paragraphs.

194. Sub-paragraphs (h) and (j) provide for giving effect to SHA paragraph 51 by the ICIR making reports to the IRG which might recommend themes for investigation. In addition, following the recommendations made in the Haass-O'Sullivan proposals, the model treaty also notes that these reports could identify classes of person who have and have not cooperated with the ICIR. The drafting committee recommends that the Code of Practice provide for these reports to be published. This would both be in line with the principle of transparency and would also contribute to public confidence in the operation of the Commission. These arrangements for reporting to the IRG eschew any suggestion that the IRG would have a managerial or supervisory role over the ICIR which would compromise its independence.

\section{Paragraph 5 Appointment}

195. Sub-paragraphs (1) to (6) largely follow the appointment procedure noted in paragraph 44 SHA. Sub-paragraph (3) provides that the two members of the Commission nominated by the First and Deputy First Ministers are formally appointed by the two governments. This is to reflect the fact that the ICIR is to be established as an international body on the basis of an inter-state treaty; it is therefore important that the contracting state parties have formal control of the appointment process.

196. Sub-paragraph (8) lays out criteria which amount to a personal specification for those to be appointed as Commissioners. The drafting committee thinks it is important that these criteria be laid out in the Founding Agreement in order to ensure, as far as possible, that all people and groups in these islands are able to have confidence in the impartiality and qualifications of those appointed.

197. Sub-paragraph (9) requires that, within the limits of anti-discrimination legislation, the two governments work together to ensure that at least two of the Commissioners are women.

\section{Paragraph 6 Tenure}

198. In order to ensure the independence and autonomy of the Commissioners, this paragraph lays down the limited circumstances in which a Commissioner may be dismissed and how substitute appointments should occur.

\section{Paragraph 7 Remuneration and allowances}

199. This paragraph states that the Commissioners should work full time and be appropriately remunerated.

\section{Paragraph 8 Secretariat}

200. In a further measure to ensure independence, this paragraph provides for the Commissioners to appoint their own staff. It also requires that staff appointed have the same qualities of expertise, independence and impartiality as required of Commissioners in paragraph 5(8).

\section{Paragraph 9 Funding}

201. This paragraph provides for adequate funding (see paragraph 94 above) and transparent accounting procedures. 


\section{Paragraph 10 Independence}

202. This paragraph provides that the ICIR be independent and have complete operational autonomy. Sub-paragraph (3) specifies that the operations of the ICIR are not to be constrained by the actions of other investigative bodies including the HIU. It also specifically allows the ICIR to require the provision of information from the HIU or other public bodies in order to assess the reliability of information otherwise provided. It will be necessary for there to be protocols or a memorandum of understanding between the HIU and the ICIR in order that there be no contamination of HIU investigations by reason of enquiries made by the ICIR and to regulate other aspects of cooperation.

\section{Paragraph 11 Commencing an information retrieval process}

203. This paragraph provides that the ICIR may commence an information retrieval process either in response to requests from victims and survivors or in response to requests from persons with information. Sub-paragraph (2) makes clear that this process can be initiated regardless of other investigations in to the same matter.

\section{Paragraph 12 Engagement with victims and survivors}

204. This paragraph expands on the function of engaging with victims. Sub-paragraph (1) stresses the voluntary character of the engagement and that a victim can withdraw at any time. Sub-paragraph (2) ensures that victims are warned that engagement might have legal consequences such as, in some circumstances, affecting the likelihood of successful future prosecutions, in spite of the protections built into the process. Sub-paragraph (3) provides that support must be given to victims during and after the process. Dealing with victims is going to be one of the most difficult and sensitive areas of work for the ICIR. Some of the matters that might be included in a Code of Practice are the need to work with victims' organisations, how to work with disparate or divided families, how support should be given to victims, and the nature of the actual process to be followed by those victims who wish to engage with the Commission.

\section{Paragraph 13 Reports to victims and survivors}

205. This paragraph deals with the content of reports and the protocols conditioning their contents and publication. Sub-paragraph (1) requires that the ICIR provide a report on request, which will contain at least the tests of reliability of information carried out and any new evidence received. However, sub-paragraph (3) provides that a report does not have to be given until the Commission thinks its processes are completed, but it may issue interim reports. Sub-paragraph (2) prohibits the publication of reports by the ICIR (though families would be free to do what they wish with reports).

206. Sub-paragraphs (4) and (5) provide that the ICIR may not identify individuals who have provided information to it, but may identify organisations who may be responsible for any acts or omissions recorded. Sub-paragraph (6) means that no report can contain information that might put an individual's life at risk. Sub-paragraph (7) provides that those providing information will be given relevant privileges and immunities (see paragraph 97 above).

\section{Paragraph 14 Expenses}

207. This paragraph provides that the expenses of victims and other people cooperating with the Commission may be paid and that other support might be offered. The practical implications of this will need to be detailed in a Code of Practice. 


\section{Paragraph 15 Obtaining information}

208. This paragraph is the foundation for the power suggested in section 35(2) of the Model Bill (see comments in paragraph 98 above) to compel public authorities to provide information. Sub-paragraph (3) permits the ICIR to seek information outside these islands and diplomatic support from the two governments is to be provided. Sub-paragraph (4) makes it clear that the ICIR is not to be regarded as a form of de-commissioning body or as providing an amnesty mechanism for the handing in of weapons or other articles which may be relevant to criminal investigations.

209. It is suggested that the Code of Practice might address matters such as how the commission should seek to engage with possible information providers, how meetings will be conducted, and how information recovery might be a process involving several meetings and processes.

\section{Paragraph 16 Holding and disclosing information}

210. This paragraph provides that the ICIR shall hold information in a secure and ECHRcompliant manner and that it will not disclose either information or the identity of information providers to law enforcement or other public authorities. The code of practice should require the Commission to set up data management systems to enable it to do data analysis and cross-check between information provided. Section 32(6) of the Model Bill stipulates that the archives of the ICIR should be held securely and confidentially for 50 years in a manner to be determined by the ICIR.

\section{Paragraph 17 Use of information}

211. This paragraph is the foundation for the power provided for in Section 35(3) and (4) which makes any information given to the ICIR inadmissible in legal proceedings. Subparagraph (2) notes that information already in the possession of a public authority may be so used, even if it is provided to ICIR, and also that a prosecution of a person may proceed in reliance on evidence obtained elsewhere even if that information is also provided to the ICIR.

\section{Paragraph 18 Offences}

212. This paragraph makes provision for the offences detailed. Please note the comments made on behalf of the drafting committee in paragraph 100 above.

\section{Paragraph 19 Entry into force}

213. This paragraph provides that the Agreement will enter into force on the first day of the second month after completion of legal formalities by the state Parties.

\section{Paragraph 20 Duration of Agreement}

214. This paragraph provides the Agreement will continue in force until terminated by mutual agreement by the two governments, but it will continue to have effect after such termination in relation to meeting liabilities or disposing of remaining assets of the Commission. 